The impact of delays on the welfare effects of on-track competition: The case of transfer passengers with operator-tied tickets

by

Christina Brand and Gernot Sieg

Institute of Transport Economics Münster

Working Paper

No. 28

December 2019 


\section{(c) Westfälische Wilhelms-Universität (WWU),}

Institute of Transport Economics, 2019

\section{Address}

Institut für Verkehrswissenschaft

Am Stadtgraben 9

D 48143 Münster, Germany

\section{Telephone}

+4925183-22994

\section{Fax}

+4925183-28395

\section{E-Mail}

verkehrswissenschaft@uni-muenster.de

\section{Website}

http://www.iv-muenster.de

All rights reserved.

Any reproduction, publication and reprint in the form of a different publication, whether printed or produced electronically, in whole or in part, is permitted only with the explicit written authorisation of the Westfälische Wilhelms-Universität, Institute of Transport Economics, or the author(s).

The views expressed in this paper do not necessarily reflect those of the Institute of Transport Economics or the WWU.

The Working Paper Series seeks to disseminate economic research work by the WWU, Institute of Transport Economics staff and visitors. Papers by researchers not affiliated with the WWU Institute of Transport Economics may also be considered for publication to the extent that they have been presented at research seminars/workshops organised by the institute.

The working papers published in the Series constitute work in progress circulated to stimulate discussion and critical comments. Views expressed represent exclusively the authors' own opinions.

The Series is managed by the Director of the Institute of Transport Economics. 


\title{
The impact of delays on the welfare effects of on-track competition: The case of transfer passengers with operator-tied tickets
}

\author{
By Christina Brand* and Gernot Sieg*
}

\begin{abstract}
When connecting trains may be missed due to delays, and passengers are insufficiently flexible due to operator-tied ticketing, ontrack competition may reduce effective frequency. We analyze passengers who share $\alpha-\beta-\gamma-$ preferences for being on time and a price-sensitive demand, but differ in the preferred arrival time. If the probability of missing a connection due to a delay is sufficiently high, both producer and consumer surplus in a duopoly with reduced effective frequency is smaller than in the monopoly case. Apart from reducing unpunctuality, ensuring the transferability of tickets, and switching to competition for the market, may constitute (regulatory) remedies.

JEL: L92, L98, R48
\end{abstract}

\section{Introduction}

Since the beginning of the 1990s, the European Commission has been attempting to foster competition in the railway sector, in order to raise efficiency and to improve the intermodal competitiveness of rail as the most environmentally friendly traffic mode. Accordingly, rail freight transport and international passenger rail services are now open to competition. Opening national passenger rail services to competition as well, as announced in the Fourth Railway Package, will complete the liberalization process. The European Commission thereby aims at competition for the market by means of franchising for non-profitable (usually short-distance) services and open access with competition in the market, also called on-track competition, for commercial (usually long-distance) services (Perennes, 2017).

In some European countries, open access for long-distance passenger rail services already exists (Beria and Grimaldi, 2017). Nevertheless, on-track competition is non-marginal in just a few of them (i.e. Italy, Austria, Czech Republic and Sweden). At this point, one could compare the regulatory frameworks in the respective countries to determine whether open access alone can foster sufficient on-track competition. Many authors ${ }^{1}$ have their doubts.

We, however, would rather pose the question of whether in this market segment, on-track competition is really desirable in all circumstances. In this paper, we analyze the welfare effect of on-track competition, when connecting trains may be missed due to delays, and tickets are operator-tied. We show that, depending on the probability of missed connections, on-track competition can be welfare-

* University of Münster, Institute of Transport Economics, Am Stadtgraben 9, 48143 Münster, Germany.

The final publication in "Research in Transportation Economics" is available online at: https://doi.org/10.1016/j.retrec.2019.100801

Link (2004), Nash and Preston (1992), Preston et al. (1999), Nash (2010), Nash et al. (2013), Perennes (2017), Feuerstein et al. (2018). 
reducing. We offer a formal model supporting the proposition formulated by Nash and Preston (1992, p. 10): "successful entry which did not totally displace the incumbent operator would lead to [a] loss of economies of density, and may also disbenefit passengers". This is arguably "the most potent argument for the singular provision of train services" (Starkie, 1993, p. 53).

The German railway network and the transport services offered have some unique features that justify the assumptions of our model. In contrast to France or Spain (Zembri and Libourel, 2017), for example, many cities (and stations) are scattered throughout the country and there is no central city that serves as the hub or main destination. Furthermore, the supply of fast trains, most of which do not confirm to the high-speed definition of $250 \mathrm{~km} / \mathrm{h}$, but are fast enough to compete with car and air travel up to distances of $800 \mathrm{~km}$, is relatively dense. As a result, many passengers have to change long-distance trains at one station or more. $^{2}$

In a network with scarce capacity, delay is easily transmitted to subsequent trains and often cannot be absorbed by spare tracks. Gibson et al. (2002) present evidence that delay increases exponentially if the network approaches full capacity. In Germany, only some tracks are used exclusively for High Speed Rail (HSR). Most tracks are used simultaneously by slower trains, which intensifies the problem of scarce capacity and delays. Thus, long-distance trains follow a timetable, but are not always able to be on time, ${ }^{3}$ so that connecting trains may be missed, ${ }^{4}$ and passengers have to make new plans. Since no seat reservation is required and tickets are valid on the next train (even those of a higher type like ICE), they do not buy a new ticket but merely get onto the next available train.

Currently, almost all long-distance passenger rail services are offered by Deutsche Bahn Fernverkehr, the still state-owned train operating company (TOC). If there were on-track competition, the next available train could be operated by a competing TOC. Since tickets are usually only valid on trains of the issuing TOC, passengers missing a connecting train then could not merely use the next available train (or they would have to be willing to buy new tickets), but would have to wait for the next train of the TOC they chose at the beginning of their journey. This also applies, for example, for cross-border traveling passengers with through tickets $^{5}$ having to change trains at the border. If on both sides of the border national on-track competition existed, the TOC operating the next train out in cases of a missed connection, would not necessarily be part of the initial transport contract. Thus, passengers would suffer from a reduced "effective frequency" (Nash et al., 2013, p. 192) and thus higher schedule delay costs.

In order to analyze this aspect of on-track competition from the perspective of welfare economics, in our model of a duopoly market for long-distance passenger rail services, we assume that the combined schedule of individual TOCs yields an interlaced structure of departure times, i.e. a departure of one TOC is followed by a departure of the other one. This is the equilibrium outcome in the van Reeven

2 Deutsche Bahn Fernverkehr reports for 2017 that $14.5 \%$ of their passengers used two, and $1 \%$ three or more long-distance trains on their journey, so they had to change long-distance trains at least once.

3 Deutsche Bahn Fernverkehr reports for 2017 that only $78.5 \%$ of long-distance trains were on time, defined as less than 6 minutes late at each regular station including the final destination.

4 Deutsche Bahn Fernverkehr reports for 2017 that $13.8 \%$ of booked transfers with a scheduled transfer time less than 30 minutes were missed.

5 Through ticket means a ticket or tickets representing a transport contract for successive railway services operated by one or several railway undertakings, Article 3 of Regulation (EC) No. 1371/2007. 
(2006) horizontal product differentiation model with two dimensions (i.e. departure time and service quality). For the sake of simplicity, we abstain from service quality differentiation. In this case, unregulated timetable competition results in unstable service patterns, because of the lack of a pure strategy equilibrium (van Reeven and Janssen, 2006). However, van der Weijde et al. (2014) show in a Hotelling model with price-sensitive demand and asymmetric distance costs, departure times are scheduled closer together than optimal and should be of interest to regulators. Our assumption of interlacing, equidistant departure times is the welfare-maximizing regulation (Broman and Eliasson, 2017).

Furthermore, on-track competition may result in higher or lower frequencies of TOCs and therefore may or may not reduce passengers' schedule delay costs. We assume overall frequency to be the same as in the monopoly by symmetrically allocating the tracks to both TOCs in the duopoly. ${ }^{6}$ The constant overall frequency assumption is reasonable, if tracks are operating at full capacity. So is the symmetry assumption, since comparable supply is considered to be a longterm sustainable form of on-track competition (Beria and Grimaldi, 2017). This is especially true, if TOCs offer connecting trains and passengers anticipate the problem of missed connections. Apart from departure times, frequency and service quality, TOCs can compete on fares, speed, stops and other characteristics (Tomeš et al., 2016). For simplicity, we concentrate on fares only.

According to Johnson and Nash (2012), on-track competition, on the one hand, entails a loss of economies of density, which leads to higher costs for the competing TOCs. On the other hand, competitive pressure makes them work more efficiently. Because the overall effect on cost is ambiguous (Friebel et al., 2010) we assume that the TOCs' costs remain unchanged, compared to the monopoly case. Among others, Johnson and Nash (2012) further stress that on-track competition has to increase demand in order to be welfare-enhancing. To allow for the possibility of an increased demand for train travel, we assume this demand to be elastic. Thus, passengers anticipating the possibility of missed connections, demand significantly more train tickets if on-track competition lowers the full price of traveling by train, which consists of the fare and schedule delay costs.

Our paper is related to the literature on on-track competition and its effect on overall welfare. Preston et al. (1999) analyze several scenarios of duopolistic on-track competition, for example, including product differentiation. They present simulation results for the games they consider and conclude that on-track competition usually cannot benefit passengers more than it harms producers, and therefore reduces overall welfare. Although Preston et al. (1999) recommend introducing interchangeable tickets, they do not consider connecting trains that may be missed, in the context of which non-interchangeable tickets are more of a problem.

Alvarez-SanJaime et al. (2015) analyze on-track competition between two TOCs on a HSR line and a competing air transport service operator with private and/or public operators and endogenous service frequency. Private operators are assumed to maximize profits, whereas a public operator maximizes social welfare subject to a break-even constraint. Simulation results show that the entry of a private TOC increases welfare only if it entails very large increases in rail-traffic demand.

6 Bergantino et al. (2015), however, show that in Italy, on-track competition resulted in a substantial increase in (overall) frequency. The Italian market differs from the German market, especially regarding the share of passengers who have to change trains (crucial assumption of our model), and the reduction of access charges in 2014 that helped to finance the increased frequency (?). 
Alvarez-SanJaime et al. (2015) stress that such welfare gains are substantially larger if the incumbent TOC is not privatized, but remains public. AlvarezSanJaime et al. (2016) focus on the vertical structure and endogenous access charges when analyzing the introduction of competition on HSR lines. They find that on-track competition generates larger welfare gains if infrastructure and rail operations are vertically integrated and if there is marginal access pricing. And again, if market entry does not generate enough demand, it can not be welfareenhancing at all.

Broman and Eliasson (2017) study a duopoly market for passenger rail services and thereby assume that price competition occurs between trains with close departure times. They show that welfare increases when moving from a profitmaximizing monopoly to competition, if regulation can prevent TOCs from purchasing the respective competitor's access rights and restoring monopoly this way. If then TOCs offer equally many departures, and a departure of one TOC is always followed by a departure of the other, welfare is maximized. Thus, the number and allocation of slots is of great importance.

Cherbonnier et al. (2018) pose the question of whether competition should be introduced to the market for long-distance passenger rail services rather by means of franchising than by an open access mechanism. Therefore, they compare the outcomes of competition for the market and on-track competition, by simulating for two relations in France, a differentiated-products oligopoly model allowing for inter- and intra-modal competition. The results show that the effect of ontrack competition is uncertain, since it is not clear that competition can cause downward pressure on fares similar to the tariff distortions in the monopoly case (e.g. in the form of price-regulation or a deterrence strategy of the monopolist). But it is possible to maintain such tariff distortions and generate efficiency gains as well, when introducing competition for the market. This speaks in favor of organizing competition by means of franchising.

Although most of the above-mentioned articles challenge the proposition that on-track competition, from the perspective of welfare economics, is always desirable, none of these authors considers operator-tied ticketing in connection with delays and missed connections, as we do.

\section{The Model}

In order to analyze the welfare effect of on-track competition, when connecting trains may be missed due to delays and tickets are operator-tied, we consider passengers who want to travel from $A$ to $C$ and have to change trains at $B$. They start planning their travel backwards, i.e. choose trains whose expected arrival times suit them best. Of course, fare and travel time also influence the passengers' decision. Passengers share $\alpha-\beta-\gamma-$ preferences for avoiding travel time, being early and being late, respectively. Thus, $\alpha$ represents the marginal opportunity cost of travel time, whereas $\beta$ and $\gamma$ represent the marginal opportunity costs of being early and late (Vickrey, 1969; Arnott, 1990). We assume $\gamma>\alpha>\beta>0$, i.e. passengers rate being late worse than bearing additional travel time or being early (Small, 1982). Passengers differ in their desired arrival time $\theta \in(-\infty, \infty)$.

To avoid asymmetric situations at the beginning and end of the analyzed time period, we only consider one time period including two trains and implicitly assume that there is an infinite number of similar time periods. Thus, there are similar passengers and similar track allocations in each period, so that the equi- 
librium prices of the whole game constitute an infinite sequence of the equilibrium prices in one of the periods. ${ }^{7}$ In $A$, as well as in $B$, we consider train 1 using the slot at time $t_{1}=0$ and train 2 using the slot at time $t_{2}=1 / 2,{ }^{8}$ (see Figure 1 ), and a track authority allocating these slots either to a monopolist (market index $m$ ) or in turns to competing duopolists (market index $d$ ). The game we consider consists of only one stage, in which TOCs choose fares simultaneously, given the allocated departure times.

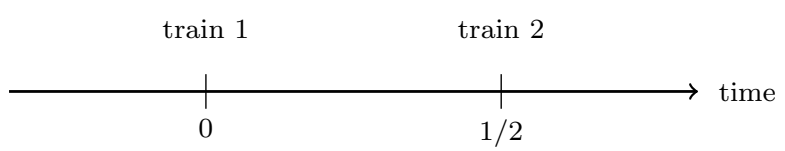

Figure 1. : Departure times of train 1 and train 2, in $A$ as well as in $B$

If trains are on time, travel time from $A$ to $B$ is normalized to 0 , which applies for the travel time from $B$ to $C$ and the transfer time at $B$ in any event. To incorporate delays, however, we assume that the train from $A$ to $B$ is not always on time. There is no consensus in the empirical literature concerning the distribution of train arrival delays. Whereas Schwanhäußer (1974) and Goverde (2005) find that arrival-delay data for trains follows a negative exponential distribution, others use the Weibull, gamma or lognormal distribution to model (late) train arrivals (Yuan, 2006). According to Bergström and Krüger (2013), train-delay distributions generally exhibit thick tails, i.e. there are usually many minor, and just a few substantial delays. To simplify the analysis, it is reasonable to assume delays to be less than $1 / 2$, so that passengers always manage to catch the next train out, if they miss a connection due to a delay.

We can further simplify by assuming that there is a probability of a delay $0<\psi<1$. By additionally assuming $\psi<\beta /(\beta+\gamma)$, we avoid a situation in which the probability of a delay is so large that it would be optimal to choose the departure time on the assumption that the train is delayed, and therefore to always choose an earlier train. Because there is no transfer time at $B$ every delay results in a missed connection. ${ }^{9}$ A ticket is valid on all trains of the TOC that issued the ticket, but not on trains of a competing TOC. This makes the monopoly situation attractive to passengers, because they are more flexible in the event of a missed connection. In the monopoly case, each train and therefore the train after the missed one is operated by the monopolist, and the passengers' tickets are valid for that train. In the duopoly case, the next train is operated by a competitor. Because it is expensive to buy a new ticket and forfeit the original one, we assume that passengers wait for the next train of the TOC they chose at the beginning of their journey. This is rational if the opportunity costs of waiting and arriving even later are less than the price of the new ticket. ${ }^{10}$

7 The results are identical to a Salop (1979) circle model when assuming that train 1 can properly serve the whole upper semi circle.

8 The index $j \in\{1,2\}$ then can be used for train $j$ using the slot at time $t_{j}=(j-1) / 2$.

9 Therefore, $\psi$ denotes the probability of a delay as well as the probability of missing a connection. Furthermore, the results do not change if we assume a transfer time $t>0$ and a probability $\bar{\psi}$ with which the delay is larger than the transfer time. However, we assume that competition does not change the transfer times.

10 Operator-tied ticketing could also mean that a public operator accepts a private operator's tickets in cases of missed connections, but not vice versa. See chapter 3 for a discussion of relaxing this assumption. 
Each passenger forms expectations about the associated opportunity cost of time when deciding on which train, i.e. for which departure time to buy a ticket. This includes the schedule delay cost resulting from arriving earlier or later than desired, and the opportunity cost of travel time. The opportunity cost of time depends on the market form because in the event of a missed connection, travel time increases from 0 to the headway $h^{i}$ in the respective market form $i$, which is $h^{m}=1 / 2$ and $h^{d}=1$. Accordingly, the full price $p_{j}^{i}$ a passenger of type $\theta$ using train $j$ has to pay, is the fare $f_{j}^{i}$ plus the expected opportunity cost of time $g_{j}^{i}$, both may differ depending on the market form $i \in\{m, d\}$ :

$$
p_{j}^{i}(\theta)=f_{j}^{i}+g_{j}^{i}(\theta) .
$$

Consequently, depending on the market form $i$, there is a passenger with a desired arrival time $\tilde{\theta}_{1}^{i}$, who is indifferent between buying a ticket for train 1 departing at 0 and buying a ticket for train 2 departing at $1 / 2$ :

$$
\begin{aligned}
& f_{1}^{i}+\psi\left(\alpha h^{i}+\gamma\left(h^{i}-\tilde{\theta}_{1}^{i}\right)\right)+(1-\psi) \beta \tilde{\theta}_{1}^{i} \\
& =f_{2}^{i}+\psi\left(\alpha h^{i}+\gamma\left(1 / 2+h^{i}-\tilde{\theta}_{1}^{i}\right)\right)+(1-\psi) \gamma\left(1 / 2-\tilde{\theta}_{1}^{i}\right) .
\end{aligned}
$$

Accordingly, assuming the fare for the train departing at time 1 equals $f_{1}^{i}$, a passenger in market $i$ with a desired arrival time $\tilde{\theta}_{2}^{i}$ is indifferent between the train departing at $1 / 2$ and the train departing at 1 :

$$
\begin{aligned}
& f_{2}^{i}+\psi\left(\alpha h^{i}+\gamma\left(1 / 2+h^{i}-\tilde{\theta}_{2}^{i}\right)\right)+(1-\psi) \beta\left(\tilde{\theta}_{2}^{i}-1 / 2\right) \\
& =f_{1}^{i}+\psi\left(\alpha h^{i}+\gamma\left(1+h^{i}-\tilde{\theta}_{2}^{i}\right)\right)+(1-\psi) \gamma\left(1-\tilde{\theta}_{2}^{i}\right) .
\end{aligned}
$$

Solving equations 2 and 3 shows that the indifferent passengers in market $i$ prefer times

$$
\tilde{\theta}_{1}^{i}=\frac{\gamma+2\left(f_{2}^{i}-f_{1}^{i}\right)}{2(1-\psi)(\beta+\gamma)} \text { and } \tilde{\theta}_{2}^{i}=\frac{1}{2}+\frac{\gamma+2\left(f_{1}^{i}-f_{2}^{i}\right)}{2(1-\psi)(\beta+\gamma)}
$$

Passengers with a desired arrival time $\theta \in\left[0, \tilde{\theta}_{1}^{i}\right) \cup\left[\tilde{\theta}_{2}^{i}-1,0\right)$ take train 1 departing at 0 , whereas those with a desired arrival time $\theta \in\left[\tilde{\theta}_{1}^{i}, \frac{1}{2}\right) \cup\left[\frac{1}{2}, \tilde{\theta}_{2}^{i}\right)$ take train 2 departing at 1/2 (see Figure 2).

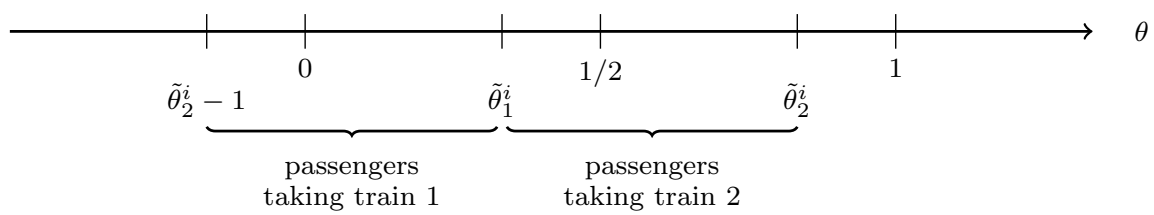

Figure 2. : Indifferent passenger types $\theta$ and departure time choice

Each passenger of type $\theta$ either refrains from traveling or switches to other modes of transport, if the full price of traveling by train $p_{j}^{i}$ is perceived as too 
high. We assume an elastic passenger demand of $d_{j}^{i}(\theta)=a-b p_{j}^{i}(\theta)$ with $a, b>0$. Hence, a passenger's maximum potential demand $a$ for traveling by train from $A$ to $C$ is the same for each type $\theta$.

Due to the symmetry assumption, it would not pay the monopolist to charge a higher fare for one of the offered departure times than for the other. This means that at equilibrium, $f_{1}^{m}=f_{2}^{m}=f^{m}$, so that the indifferent passengers are of type

$$
\tilde{\theta}_{1}^{m}=\frac{\gamma}{2(1-\psi)(\beta+\gamma)} \text { and } \tilde{\theta}_{2}^{m}=\frac{1}{2}+\frac{\gamma}{2(1-\psi)(\beta+\gamma)}=\frac{1}{2}+\tilde{\theta}_{1}^{m} .
$$

Here, one can see the intuition behind our assumption concerning the probability of missing a connection. Since we assume $\psi<\beta /(\beta+\gamma), \tilde{\theta}_{1}^{m}$ is between 0 and $1 / 2$ and $\tilde{\theta}_{2}^{m}$ between $1 / 2$ and 1 . Otherwise, passengers would probably have chosen earlier trains in the first place to be on the safe side, and equations 2 and 3 and thus 4 and 5 would no longer hold.

The monopolist faces a demand for train 1 departing at 0 of

$$
\begin{aligned}
d_{1}^{m}= & \int_{0}^{\tilde{\theta}_{1}^{m}} a-b p_{1}^{m}(\theta) d \theta+\int_{\tilde{\theta}_{2}^{m}-1}^{0} a-b p_{1}^{m}(\theta) d \theta \\
& =\frac{1}{8}\left(4 a-b\left(2 \psi(\alpha+\gamma)+\gamma-\frac{\gamma^{2}}{(1-\psi)(\beta+\gamma)}+4 f^{m}\right)\right)
\end{aligned}
$$

and for train 2 departing at $1 / 2$ of

$$
d_{2}^{m}=\int_{\tilde{\theta}_{1}^{m}}^{\tilde{\theta}_{2}^{m}} a-b p_{2}^{m}(\theta) d \theta=d_{1}^{m} .
$$

At equilibrium, the demand for train 1 is equal to the demand for train 2, i.e. $d_{1}^{m}=d_{2}^{m}=d^{m}$.

The cost of operating a train consists of fixed costs per train $c_{t}$ including access charges, and marginal costs per passenger of $c$. The profit accruing to the monopolist operating two trains is

$$
\Pi^{m}=2\left(f^{m}-c\right) d^{m}-2 c_{t},
$$

which is maximized if the fares are

$$
\tilde{f}^{m}=\frac{1}{4}\left(\frac{2 a}{b}-\psi(\alpha+\gamma)+\frac{\gamma^{2}}{2(1-\psi)(\beta+\gamma)}-\frac{\gamma}{2}\right)+\frac{c}{2} .
$$

Let us now consider what will happen to equilibrium fares in the duopoly. Beria and Grimaldi (2017) show that entrants can follow a strategy of cost leadership as well as product differentiation. Without such comparative advantages, entry is only possible if the focus is on (niche) markets which are largely unserved, where access charges are low, or where demand is particularly high. We focus on the latter case, where tracks are limited and the market is lucrative, and therefore assume that the entrant bears the same costs as the (former) monopolist and that both TOCs offer non-differentiated products, i.e. offer the same frequency and onboard service quality. We do not analyze the phase of entry, which involves getting 
tracks and (possibly) strategic behavior of the incumbent (entry deterrence), but an equilibrium of successful entry resulting in a symmetric duopoly.

In order to compute equilibrium fares in the duopoly, the demand for train 1 operated by one of the two TOCs is

$$
d_{1}^{d}=\int_{0}^{\tilde{\theta}_{1}^{d}} a-b p_{1}^{d}(\theta) d \theta+\int_{\tilde{\theta}_{2}^{d}-1}^{0} a-b p_{1}^{d}(\theta) d \theta
$$

and the demand for train 2 operated by the other TOC equals

$$
d_{2}^{d}=\int_{\tilde{\theta}_{1}^{d}}^{\tilde{\theta}_{2}^{d}} a-b p_{2}^{d}(\theta) d \theta
$$

Using equation 1, which incorporates the different headways in the duopoly, and equation 4 leads to quite complex expressions for $d_{1}^{d}$ and $d_{2}^{d}$ which are shown in the Appendix. Payoffs for the TOCs are profits $\Pi_{j}^{d}=\left(f_{j}^{d}-c\right) d_{j}^{d}-c_{t}$ and the resulting Nash equilibrium strategies are fares $\tilde{f}_{1}^{d}=\tilde{f}_{2}^{d}=\tilde{f}^{d}$ :

$$
\tilde{f}^{d}=\frac{1}{4}\left(\frac{2 a}{b}-(2 \alpha+\beta+3 \gamma) \psi+\frac{\beta^{2}}{(1-\psi)(\beta+\gamma)}+\beta+\frac{\beta-\gamma}{1-\psi}-\Phi_{1}\right)+\frac{c}{2}
$$

with $\Phi_{1}$ defined in the Appendix.

If trains are on time, travel time does not depend on the market type. If trains are delayed and therefore connections are missed, in the duopoly the travel time and the too-late arrival time is one headway $h^{m}$ larger. The additional cost of travel time is $\alpha h^{m}$ and the additional cost of being late is $\gamma h^{m}$, both incurred only with the probability $\psi$ of missing a connection. Therefore, the expected opportunity cost of time in the duopoly is

$$
g^{d}(\theta)=g^{m}(\theta)+\psi(\alpha+\gamma) h^{m}
$$

and the demand of a type $\theta$ passenger in the duopoly is

$d^{d}(f)=a-b\left(f+g^{d}(\theta)\right)=a-b\left(f+g^{m}(\theta)+\psi(\alpha+\gamma) h^{m}\right)=d^{m}(f)-b \psi(\alpha+\gamma) h^{m}$

which is the monopolist's demand shifted downwards by an amount $b \psi(\alpha+\gamma) h^{m}$ (see Figure 3).

A hypothetical monopolist offering two trains, but applying the duopoly rule that a ticket is not valid on the next, but only on the train after that, faces a demand $d^{d}$ that is more sensitive to fare increases than the demand $d^{m}$. Therefore, the monopolist's optimal fare $\tilde{f}^{m}$ is larger than that of the hypothetical monopolist, which is larger than the optimal fares $\tilde{f}^{d}$ of two competing duopolists facing the demand $d^{d}: \tilde{f}^{m}>\tilde{f}^{d}$, i.e. on-track competition leads to lower fares. This is one of the main arguments for fostering on-track competition.

On-track competition, however, can prolong travel times, which reduces consumer surplus. The surplus of type $\theta$ passengers in the market $i$ equals

$$
C S^{i}(\theta)=\int_{f^{i}+g^{i}(\theta)}^{a / b} a-b p d p .
$$




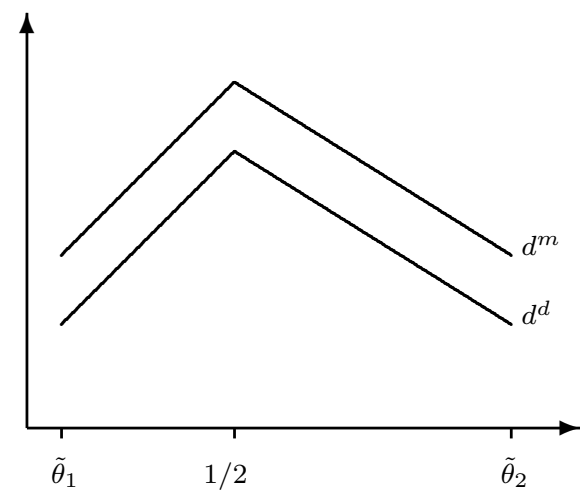

Figure 3. : Passenger type $\theta$ 's demand for the train departing at $1 / 2$ in the monopoly $d^{m}$ and the duopoly $d^{d}$ if the fares are the same

Hence, the difference in these passengers' surplus between monopoly and duopoly is described by

$$
\begin{aligned}
\Delta C S(\theta) & =C S^{m}(\theta)-C S^{d}(\theta)=\int_{\tilde{f}^{m}+g^{m}(\theta)}^{a / b} a-b p d p-\int_{\tilde{f}^{d}+g^{d}(\theta)}^{a / b} a-b p d p \\
& =\int_{\tilde{f}^{m}+g^{m}(\theta)}^{\tilde{f}^{d}+g^{d}(\theta)} a-b p d p .
\end{aligned}
$$

Since demand is non-negative, the consumer surplus difference is positive if and only if the full price of traveling by train from $A$ to $C$ is lower in the monopoly than the duopoly:

$$
\Delta C S(\theta)>0 \Longleftrightarrow \tilde{f}^{m}+g^{m}(\theta)<\tilde{f}^{d}+g^{d}(\theta) .
$$

With $g^{d}(\theta)=g^{m}(\theta)+\psi(\alpha+\gamma) h^{m}$ this holds if and only if

$$
\frac{\tilde{f}^{m}-\tilde{f}^{d}}{\psi(\alpha+\gamma)}<h^{m}
$$

In our model, headway in the monopoly is $h^{m}=1 / 2$. Therefore, we obtain

PROPOSITION 1: Consumer surplus in the monopoly is larger than in the duopoly if and only if

$$
\psi>\frac{2\left(\tilde{f}^{m}-\tilde{f}^{d}\right)}{(\alpha+\gamma)}=\bar{\psi},
$$

and $\psi>\bar{\psi}$ if

$$
\psi>\frac{2(a-b c)}{3 b(\alpha+\gamma)}=\tilde{\psi}
$$

Proof: See Appendix. 
Apparently, the sign of $\Delta C S$ does not depend on $\theta$. This implies that all passengers similarly prefer on-track competition or a monopoly.

Moreover, as the expected opportunity cost of time is smaller in the monopoly than in the duopoly, $g^{d}>g^{m}$, a monopolist demanding the same fare $f$ as a duopolist, faces a larger demand at each of the offered departure times:

$$
d^{m}(f)>d^{d}(f) \text {. }
$$

Since the market is profitable, the fares in the duopoly exceed marginal cost. Thus, the overall profit of the monopolist charging $\tilde{f}^{d}$ is larger than the aggregate profit of the duopolists:

$$
\Pi^{m}\left(\tilde{f}^{d}\right)>2 \Pi^{d}\left(\tilde{f}^{d}\right) .
$$

Since $\tilde{f}^{m}$ maximizes the monopolist's profit, it holds that $\Pi^{m}\left(\tilde{f}^{m}\right)>\Pi^{m}\left(\tilde{f}^{d}\right)$. Therefore, overall profit in the monopoly is larger than in the duopoly:

$$
\Pi^{m}\left(\tilde{f}^{m}\right)>2 \Pi^{d}\left(\tilde{f}^{d}\right),
$$

and we can state

PROPOSITION 2: If the consumer surplus is larger in the monopoly than in the duopoly, so too is welfare.

As a corollary, if the probability of missing a connection due to a delay is sufficiently high or, more precisely, exceeds a certain threshold $\bar{\psi}$, a monopoly leads to higher welfare than on-track competition in a duopoly.

The question here is what happens to this threshold if its determining factors, i.e. the $y$-intercept of the demand curve $(a)$, the slope of the demand curve $(b)$, the marginal cost per passenger $(c)$, the marginal opportunity cost of travel time $(\alpha)$ and the marginal opportunity cost of being late $(\gamma)$, change. Since $\bar{\psi}$ defined in equation 6 can only be calculated numerically, we use $\tilde{\psi}$ defined in equation 7 for comparative statics analysis. Proposition 3 provides its results.

PROPOSITION 3: For the threshold $\tilde{\psi}$ it holds

$$
\frac{\partial \tilde{\psi}}{\partial a}>0, \frac{\partial \tilde{\psi}}{\partial b}<0, \frac{\partial \tilde{\psi}}{\partial c}<0, \frac{\partial \tilde{\psi}}{\partial \alpha}<0, \frac{\partial \tilde{\psi}}{\partial \gamma}<0 .
$$

Proof: See Appendix.

If the price elasticity of demand decreases, the markup of the monopolist increases more than the fare of a duopolist, and the difference in fares increases. Hence, the probability of missing a connection has to be higher for the monopoly to generate higher consumer surplus than the duopoly. Only then can the value attributed by the passengers to the expected amount of time saved when using the next train in the event of a missed connection be large enough to overcompensate for their loss of consumer surplus due to excessive pricing. Since a larger $y$-intercept of the demand curve $a$ decreases and a steeper slope $b$ increases the price elasticity of demand, the threshold increases in $a$ and decreases in $b$.

If the marginal cost per passenger increases, the monopolist passes a smaller part of the cost increase on to the passengers, compared to the duopolist. Thus, the difference in fares decreases, and so does the threshold. 
Moreover, if the marginal opportunity cost of travel time or of being late increases, passengers weight the advantage of a shorter headway in the monopoly case more heavily. The effect on the fare difference is ambiguous. However, the respective derivatives in Proposition 3 confirm that even if the difference between monopoly and duopoly fare rose in $\alpha$ and/or $\gamma$, the threshold would nevertheless decrease. This means that the time effect is the dominant one, and ensures that the threshold $\tilde{\psi}$ decreases in the marginal opportunity cost of travel time or of being late.

In a further step, we use the calibration method of van der Weijde et al. (2014), i.e. we set $c=0, a / b=10$ and $\beta=5$, and solve the model using the software Mathematica. All numerical results confirm Proposition 3. For example, Figure 4 shows the threshold $\bar{\psi}$ as a function of $\gamma \cdot{ }^{11}$

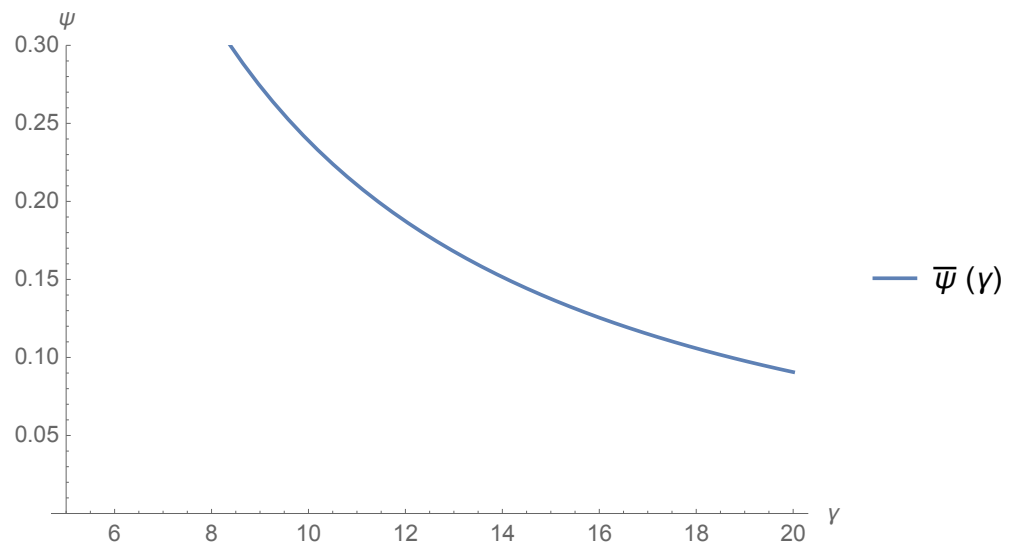

Figure 4. : Threshold of the probability of missing a connection, for on-track competition to reduce consumer surplus

It is easy to see that the threshold decreases with the opportunity cost of being late and the opportunity cost of additional travel time, respectively. In particular, this visualizes one of the comparative static results: If passengers weight the advantage of a shorter headway in the monopoly highly, it requires a relatively small probability of missing a connection to generate higher consumer surplus in the monopoly than in the duopoly. Thus, consumer preferences seem to have a strong impact on the way missed connections thwart on-track competition. In the case referred to in Figure 4, a probability of missing a connection of $13.8 \%$ as observed in Germany causes on-track competition to reduce consumer surplus, if the opportunity cost of being late is larger than about 15 and therewith the opportunity cost of additional travel time is larger than about 10.

\section{Discussion of assumptions}

In order to assess the impact of our model assumptions, we analyze whether and how the results change when the assumptions are relaxed.

11 Because van der Weijde et al. (2014) do not calibrate the opportunity cost of additional travel time $\alpha$, we assume $\alpha$ to be the arithmetic mean of $\beta$ and $\gamma$, guaranteeing that $\gamma>\alpha>\beta$ and $\gamma-\alpha=\alpha-\beta$. 
If on-track competition increases overall frequency, because additional operators entail additional departures, on-track competition will not necessarily reduce effective frequency. The effect on effective frequency depends on the number of additional departures, and their timing. An increased effective frequency benefits passengers, since it results in departure times conforming better to their preferences. Thus, with additional departures, the reduction in consumer surplus due to missed connections will decline, and if the number of departures rises sharply, consumer surplus may even rise. Whether or not additional departures increase producer surplus depends on whether or not additional demand can offset the reduction in fares and the change in costs.

We assume that on-track competition does not change TOC costs per train, for example because the downward pressure on costs is offset by the loss of economies of density. However, if newcomers simply add to the incumbent's departures, the incumbent will not lose economies of density, but may operate more costeffectively. Such a competition-induced cost reduction improves welfare and may counterbalance the negative effects of a reduced effective frequency, as described in our model.

If the equilibrium of successful entry results in an oligopoly instead of a duopoly, on-track competition will reduce effective frequency even more, so that a reduction in consumer surplus becomes more likely - but only if on-track competition does not change the overall frequency. In this case, the incumbent will suffer even more from a loss of economies of density.

Apart from the constant overall frequency and costs per train, we assume uniform pricing both for the monopoly and for the duopoly. If the monopolist uses price discrimination instead, it will usurp a large share of the consumer surplus. In the case of perfect price discrimination, i.e. individual fares for each passenger type, the monopolist will usurp the entire consumer surplus and welfare will be maximized. If the companies competing on-track are also able to achieve perfect price discrimination, on-track competition will not change this result. If the incumbent loses the ability to price discriminate because of the new entrants, consumer surplus will rise, but producer surplus will shrink. The aggregate effect is a reduction in welfare.

If we assume quality differentiation between the entrant and the incumbent TOC, as in van Reeven (2006), we really will have interlaced departures as an equilibrium strategy (instead of having to assume it). The consequences of a change in quality on welfare depend on the level of differentiation and on whether the entrant offers higher or lower quality than the incumbent. If the entrant offers a large quality improvement, it is possible that for all probabilities of missing a connection, welfare in the post-entry situation will be larger, even if tickets are operator-tied.

Furthermore, operator-tied ticketing could also mean that a public operator accepts a private operator's tickets in the event of a missed connection, but not vice versa. If one starts from this idea of asymmetric operator-tied ticketing, the time effect of on-track competition will be smaller, since passengers suffer only from a reduced effective frequency when choosing the public operator. Thus, the public operator's quality is lower than that of the private operator, and so too is the willingness to pay for public tickets. This type of quality differentiation reduces competition. Passengers using the public operator are, however, confronted with the operator-tied tickets assumed in our model and therefore prone to the possibility that welfare is reduced if connections are missed with high probability. 
In contrast, the time effect of on-track competition might be greater, if one assumes that seat reservations are compulsory. If, due to this policy, the occupancy rate increases so that there might be no excess capacity in the next available train in cases of a missed connection, the additional travel time in the duopoly will be even larger, which makes it more likely that on-track competition reduces consumer surplus. All this is obviously only valid ceteris paribus, i.e. under the key assumption of a constant or only slightly increasing overall frequency.

\section{Conclusion}

What is the effect of on-track competition in long-distance passenger rail services resulting in a duopoly with an unchanged overall frequency and an interlaced structure of departure times on overall welfare - when connections may be missed due to delays, and passengers are insufficiently flexible due to operator-tied ticketing? If travelers share $\alpha-\beta-\gamma-$ preferences for being on time and a price-sensitive demand, but differ in the preferred arrival time, the answer is: If the probability of missing a connection due to a delay is sufficiently high, producer as well as consumer surplus in a duopoly is smaller than in the monopoly case. On-track competition then reduces welfare.

In any event, the ongoing liberalization of the entire transport sector, especially the market entry of long-distance coaches, and the associated more intense intermodal competition, restrict the price-setting leeway of a railway monopolist. ${ }^{12}$ Additionally, an important share of passengers are business travelers with high opportunity costs of time, who particularly appreciate flexibility, especially if trains are late. Thus, the probability of missing a connection does not have to be especially high for on-track competition to be welfare-reducing, as passengers do not suffer from excessive monopoly fares and probably highly value the greater flexibility in cases of missed connections.

For this result our model assumptions, fitting apparently well with the German rail system/network, are crucial. Therefore, it is not directly transferable to any other European country. Policymakers in countries in which connecting traffic is a comparatively large fraction of overall rail traffic and the unpunctuality of trains is a common problem, however, should consider the following. Unpunctuality harms passengers and may also induce additional opportunity costs by, as our model shows, thwarting on-track competition. If it is not possible or economical for TOCs and infrastructure managers to reduce unpunctuality sufficiently, as it may be the case in Germany, it is necessary to ensure that time-sensitive passengers remain flexible in cases of missed connections. Then, time losses do not offset fare reductions gained and on-track competition benefits passengers as intended. According to the Regulation (EC) No. 1371/2007 of the European Parliament and of the Council of 23 October 2007 on rail passengers' rights and obligations, TOCs shall offer through tickets, where available. However, in a duopoly with TOCs selling through tickets, in cases of a missed connection, the TOC operating the next train out, is usually not part of the initial transport contract and does not accept the competitor's tickets. If it is reasonable to expect the arrival at the final destination to be delayed by more than 60 minutes, passengers can decide to buy an additional ticket for the next train out and obtain a reimbursement for

12 See White and Robbins (2012) for Britain, Aarhaug and Fearnley (2016) for Norway, Blayac and Bougette (2017) for France and Augustin et al. (2014), Knorr and Lueg-Arndt (2016), Dürr and Hüschelrath (2017) and ? for Germany. 
the segment of the original ticket not used. In this case, high transaction costs occur for the passenger, who has to apply for and acquire information about the exact amount of reimbursement, as well as for the TOC, which has to (arguably strategically) calculate a price for the non-used segment of the ticket and prevent cheating or arbitrage by passengers.

A regulation that forces TOCs to accept competitors' tickets in cases of a missed connection is associated with unintended incentives and high transaction costs. Distributing revenue fosters collusion and thus reduces the very price competition which liberalization was intended to achieve. Preventing moral hazard regarding delays or strategic fares requires complex contracts with high transaction costs. Against this background, it is an open research question as to whether this type of regulation is justifiable.

Last but not least, it should be noted that competition in the market for longdistance passengers can involve more than the price level and in particular, can be organized in a different way than we assume - namely, by means of franchising. This way of organizing competition becomes particularly relevant in the context of Switzerland's example of timetable synchronization at the national level, as Germany probably will do. Competition for the market can also imply downward pressure on fares as well as on costs. However, if the franchise does not cover the whole country, connecting trains on the same route are operated in an interlaced structure by different TOCs and delays are common, operator-tied ticketing is again a problem. This must be considered when designing franchise agreements. In order to reap the benefits of railway liberalization, it is necessary to have an appropriate framework that takes into account the circumstances of the market for long-distance passenger services, as well as the organization of the railway sector in the particular country. 


\section{Appendix}

The demand for train 1 departing at $0 d_{1}^{d}$, as well as for train 2 departing at $1 / 2 d_{2}^{d}$, are described as

$$
\begin{array}{r}
d_{1}^{d}=\frac{1}{8(\beta+\gamma)^{2}(-1+\psi)^{2}}\left(( 2 f _ { 1 } ^ { d } - 2 f _ { 2 } ^ { d } - \gamma ) \left(4 a(\beta+\gamma)(-1+\psi)+b\left(2 f_{1}^{d} \beta+2 f_{2}^{d} \beta\right.\right.\right. \\
\left.\left.+4 f_{1}^{d} \gamma+\beta \gamma+(\beta+\gamma)\left(-2\left(f_{1}^{d}+f_{2}^{d}-2 \alpha\right)+3 \gamma\right) \psi-4(\alpha+\gamma)(\beta+\gamma) \psi^{2}\right)\right)+ \\
\left(2 f_{1}^{d}-2 f_{2}^{d}-\beta+(\beta+\gamma) \psi\right)\left(4 a(\beta+\gamma)(-1+\psi)+b\left(4 f_{1}^{d} \beta+2 f_{1}^{d} \gamma+2 f_{2}^{d} \gamma+\beta \gamma\right.\right. \\
\left.\left.\left.+(\beta+\gamma)\left(-4 f_{1}^{d}+4 \alpha+3 \gamma\right) \psi-4(\alpha+\gamma)(\beta+\gamma) \psi^{2}\right)\right)\right)
\end{array}
$$

and

$$
\begin{array}{r}
d_{2}^{d}=\frac{1}{8(\beta+\gamma)^{2}(-1+\psi)^{2}}\left(( - 2 f _ { 1 } ^ { d } + 2 f _ { 2 } ^ { d } - \gamma ) \left(4 a(\beta+\gamma)(-1+\psi)+b\left(2 f_{1}^{d} \beta+2 f_{2}^{d} \beta\right.\right.\right. \\
\left.\left.+4 f_{2}^{d} \gamma+\beta \gamma+(\beta+\gamma)\left(-2\left(f_{1}^{d}+f_{2}^{d}-2 \alpha\right)+3 \gamma\right) \psi-4(\alpha+\gamma)(\beta+\gamma) \psi^{2}\right)\right)+ \\
\left(-2 f_{1}^{d}+2 f_{2}^{d}-\beta+(\beta+\gamma) \psi\right)\left(4 a(\beta+\gamma)(-1+\psi)+b\left(4 f_{2}^{d} \beta+2 f_{1}^{d} \gamma+2 f_{2}^{d} \gamma+\beta \gamma\right.\right. \\
\left.\left.\left.+(\beta+\gamma)\left(-4 f_{2}^{d}+4 \alpha+3 \gamma\right) \psi-4(\alpha+\gamma)(\beta+\gamma) \psi^{2}\right)\right)\right) .
\end{array}
$$

Each duopolist $j \in\{1,2\}$ maximizes it's profit $\Pi_{j}^{d}=\left(f_{j}^{d}-c\right) d_{j}^{d}-c_{t}$, and the fares $\tilde{f}_{1}^{d}=\tilde{f}_{2}^{d}=\tilde{f}^{d}$ in the Nash-equilibrium can be calculated, using the fact that this game is symmetric, as

$$
\tilde{f}^{d}=\frac{1}{4}\left(\frac{2 a}{b}-(2 \alpha+\beta+3 \gamma) \psi+\frac{\beta^{2}}{(1-\psi)(\beta+\gamma)}+\beta+\frac{\beta-\gamma}{1-\psi}-\Phi_{1}\right)+\frac{c}{2}
$$

with

$$
\begin{aligned}
& \Phi_{1}=\sqrt{\Phi_{2}+\Phi_{3}+\Phi_{4}+\Phi_{5}} \\
& \Phi_{2}=\left(-\psi(2 \alpha+\beta+3 \gamma)+\frac{2 a}{b}-\frac{\gamma^{2}}{(\psi-1)(\beta+\gamma)}+\beta+2 c\right)^{2} \\
& \Phi_{3}=-\frac{4 a(-\psi(\beta+\gamma)+\beta+4 c+\gamma)}{b} \\
& \Phi_{4}=-4 \alpha \beta \psi^{2}+4 \alpha \beta \psi-4 \alpha \gamma \psi^{2}+4 \alpha \gamma \psi-4 \beta \gamma \psi^{2}+3 \beta \gamma \psi+\beta \gamma-4 \gamma^{2} \psi^{2}+3 \gamma^{2} \psi \\
& \Phi_{5}=4 c\left(4 \alpha \psi+\frac{2 \gamma^{2}}{(\psi-1)(\beta+\gamma)}+\beta(\psi-1)+5 \gamma \psi+\gamma\right) .
\end{aligned}
$$

Proof of Proposition 1

Since $\psi<\beta /(\beta+\gamma)$, it holds that $f_{m}<a / 2 b+c / 2-\psi(\alpha+\gamma) / 4$. Additionally, $f^{d}>c$. Therefore, it follows

$$
\frac{f_{m}-f_{d}}{\psi(\alpha+\gamma)}<\frac{a / 2 b-c / 2-\psi(\alpha+\gamma) / 4}{\psi(\alpha+\gamma)},
$$


which is less than $1 / 2$ if and only if

$$
\psi>\frac{2(a-b c)}{3 b(\alpha+\gamma)} .
$$

Proof of Proposition 3

$$
\begin{array}{r}
\frac{\partial \tilde{\psi}}{\partial a}=\frac{2}{3 b(\alpha+\gamma)}>0, \frac{\partial \tilde{\psi}}{\partial b}=-\frac{2 a}{3 b^{2}(\alpha+\gamma)}<0, \frac{\partial \tilde{\psi}}{\partial c}=-\frac{2}{3(\alpha+\gamma)}<0 \\
\frac{\partial \tilde{\psi}}{\partial \alpha}=-\frac{2(a-b c)}{3 b(\alpha+\gamma)^{2}}<0, \frac{\partial \tilde{\psi}}{\partial \gamma}=-\frac{2(a-b c)}{3 b(\alpha+\gamma)^{2}}<0
\end{array}
$$

because $\alpha, \gamma, a, b, c>0$ and $a>b c$.

\section{REFERENCES}

Aarhaug, J. and Fearnley, N. (2016). Deregulation of the Norwegian long distance express coach market. Transport Policy, 46:1-6.

Alvarez-SanJaime, Ó., Cantos-Sanchez, P., Moner-Colonques, R., and SempereMonerris, J. J. (2015). A model of internal and external competition in a High Speed Rail line. Economics of Transportation, 4(3):178-187.

Alvarez-SanJaime, Ó., Cantos-Sanchez, P., Moner-Colonques, R., and SempereMonerris, J. J. (2016). Rail access charges and internal competition in high speed trains. Transport Policy, 49:184-195.

Arnott, R. (1990). Signalzed intersection queuing theory and central business district auto congestion. Economics Letters, 33:197-201.

Augustin, K., Gerike, R., Martinez Sanchez, M. J., and Ayala, C. (2014). Analysis of intercity bus markets on long distances in an established and a young market: The example of the U.S. and Germany. Research in Transportation Economics, $48: 245-254$.

Bergantino, A. S., Capozza, C., and Capurso, M. (2015). The impact of open access on intra- and inter-modal rail competition. A national level analysis in Italy. Transport Policy, 39:77-86.

Bergström, A. and Krüger, N. A. (2013). Modeling passenger train delay distributions - Evidence and implications. Working Paper 2013:3, Centre for Transport Studies Stockholm.

Beria, P. and Grimaldi, R. (2017). Reality and opportunities for on-track competition in HSR. In Albalate, E. and Bel, G., editors, Evaluating High-Speed Rail. Interdisciplinary Perspectives. Routledge.

Blayac, T. and Bougette, P. (2017). Should I go by bus? The liberalization of the long-distance bus industry in France. Transport Policy, 56:50-62.

Broman, E. and Eliasson, J. (2017). Market dynamics in on-rail competition. Transportation Research Procedia, 22:232-244. 
Cherbonnier, F., Ivaldi, M., Muller-Vibes, C., and Van der Straeten, K. (2018). Competition for versus in the market of long-distance passenger rail services. Review of Network Economics, 16(2):203-238.

Dürr, N. S. and Hüschelrath, K. (2017). Patterns of entry and exit in the deregulated German interurban bus industry. Transport Policy, 59:196-208.

Feuerstein, L., Busacker, T., and Xu, J. (2018). Factors influencing open access competition in the European long-distance passenger rail transport - A Delphi study. Research in Transportation Economics, 69:300-309.

Friebel, G., Ivaldi, M., and Vibes, C. (2010). Railway (de)regulation: A European efficiency comparison. Economica, 77:77-91.

Gibson, S., Cooper, G., and Ball, B. (2002). Developments in transport policy: The evolution of capacity charges on the UK rail network. Journal of Transport Economics and Policy, 36(2):341-354.

Goverde, R. M. (2005). Punctuality of railway operations and timetable stability analysis. PhD thesis, The Netherlands TRAIL Research School.

Johnson, D. and Nash, C. (2012). Competition and the provision of rail passenger services: A simulation exercise. Journal of Rail Transport Planning and Management, 2(1-2):14-22.

Knorr, A. and Lueg-Arndt, A. (2016). Intercity bus deregulation in Germany Intramodal and intermodal effects after two years. Research in Transportation Economics, 59:323-329.

Link, H. (2004). Rail infrastructure charging and on-track competition in Germany. International Journal of Transport Management, 2:17-27.

Nash, C. (2010). European rail reform and passenger services - The next steps. Research in Transportation Economics, 29(1):204-211.

Nash, C., Nilsson, J.-E., and Link, H. (2013). Comparing three models for introduction of competition into railways. Journal of Transport Economics and Policy, 47(2):191-206.

Nash, C. and Preston, P. M. (1992). Barriers to entry in the railway industry. Working Paper 354, Institute of Transport Studies, University of Leeds.

Perennes, P. (2017). Open access for rail passenger services in Europe: Lesson learnt from forerunner countries. Transportation Research Procedia, 25:358367.

Preston, J., Whelan, G., and Wardman, M. (1999). An analysis of the potential for on-track competition in the British passenger rail industry. Journal of Transport Economics and Policy, 33(1):77-94.

Salop, S. C. (1979). Monopolistic competition with outside goods. The Bell Journal of Economics, 10(1):141-156.

Schwanhäußer, W. (1974). Die Bemessung der Pufferzeiten im Fahrplangefüge der Eisenbahn. PhD thesis, Verkehrswissenschaftliches Institut der RheinischWestfälischen Technischen Hochschule Aachen. 
Small, K. A. (1982). The scheduling of consumer activities: Work trips. The American Economic Review, 72(3):467-479.

Starkie, D. (1993). Train service co-ordination in a competitive market. Fiscal Studies, 14(2):53-64.

Tomeš, Z., Kvizda, M., Jandová, M., and Rederer, V. (2016). Open access passenger rail competition in the Czech Republic. Transport Policy, 47:203-211.

van der Weijde, A. H., Verhoef, E. T., and van den Berg, V. A. C. (2014). A hotelling model with price-sensitive demand and asymmetric distance costs: The case of strategic transport scheduling. Journal of Transport Economics and Policy, 48:261-277.

van Reeven, P. (2006). Scheduling in on-route competition. Journal of Transport Economics and Policy, 40(2):225-254.

van Reeven, P. and Janssen, M. (2006). Stable service patterns in scheduled transport competition. Journal of Transport Economics and Policy, 40(1):135160.

Vickrey, W. S. (1969). Congestion theory and transport investment. American Economic Review, 59:251-261.

White, P. and Robbins, D. (2012). Long-term development of express coach services in Britain. Research in Transportation Economics, 36(1):30-38.

Yuan, J. (2006). Stochastic modelling of train delays and delay propagation in stations. PhD thesis, The Netherlands TRAIL Research School.

Zembri, P. and Libourel, E. (2017). Towards oversized high-speed rail systems? Some lessons from France and Spain. Transportation Research Procedia, $25: 368-385$. 
Westfälische Wilhelms-Universität Münster, Institute of Transport Economics, Working Paper Series

18 "Residential Parking in Vibrant City Districts"

by Inga Molenda and Gernot Sieg, September 2013

19 "Are commercial ceilings adequate for the regulation of commercial overload on free-to-air TV channels?"

by Julia Rothbauer and Gernot Sieg, September 2013

20. "Welfare Effects of Subsidizing a Dead-End Network of Less Polluting Vehicles" by Antje-Mareike Dietrich and Gernot Sieg, October 2013

21. "Costs and benefits of a bicycle helmet law for Germany" by Gernot Sieg, March 2014

22. "Time-Declining risk-adjusted social discount rates for transport infrastructure planning"

by Kathrin Goldmann, April 2017

23. "To pay or not to pay for parking at shopping malls - A rationale from the perspective of two-sided markets"

by Inga Molenda and Gernot Sieg, November 2017

24. "A duopoly of transportation network companies and traditional radio-taxi dispatch service agencies"

by Thorsten Heilker and Gernot Sieg, November 2017

25. "Airport Efficiency in Pakistan - A Data Envelopment Analysis with Weight Restrictions"

by David Ennen and Irem Batool, November 2017

26. "Economic implications of phantom traffic jams: Evidence from traffic experiments" by Kathrin Goldmann and Gernot Sieg, December 2018

27. "Evaluating the Transport-Mode-Specific Trade Effects of Different Transport Infrastructure Types"

by Jan Wessel, February 2019

28. "The impact of delays on the welfare effects of on-track competition: The case of transfer passengers with operator-tied tickets"

by Christina Brand and Gernot Sieg, December 2019

For a complete list of Working Papers published by Westfälische Wilhelms-Universität Münster, Institute of Transport Economics, please visit the website (http://www.ivmuenster.de) 